\title{
Ginsenoside Rg1 attenuates high glucose-induced endothelial barrier dysfunction in human umbilical vein endothelial cells by protecting the endothelial glycocalyx
}

\author{
TINGTING ZHU ${ }^{1-4}$, HONGLIAN WANG ${ }^{4}$, LI WANG $^{4}$, XIA ZHONG $^{4}$, WEI HUANG ${ }^{1,2}$, XIAN DENG $^{1,2}$, \\ HENGLI GUO $^{1,2}$, JIANFENG XIONG ${ }^{1,2}$, YOUHUA XU ${ }^{1,2}$ and JUNMING FAN ${ }^{1,4,5}$ \\ ${ }^{1}$ Department of Traditional Chinese and Western Medicine, Faculty of Chinese Medicine; ${ }^{2}$ State Key Laboratory of \\ Quality Research in Chinese Medicine, Macau University of Science and Technology, Taipa, Macau 999078; \\ ${ }^{3}$ Department of Nephrology, The First Affiliated Hospital of Southwest Medical University, Luzhou, Sichuan 646000; \\ ${ }^{4}$ Department of Nephrology, The Research Center of Combined Traditional Chinese and Western Medicine, Affiliated \\ Traditional Chinese Medicine Hospital, Southwest Medical University, Luzhou, Sichuan 646000; ${ }^{5}$ Department of \\ Traditional Chinese and Western Medicine, Chengdu Medical College, Chengdu, Sichuan 610000, P.R. China
}

Received July 7, 2017; Accepted December 1, 2017

DOI: $10.3892 /$ etm.2019.7378

\begin{abstract}
Disruption of the endothelial barrier is essential for vascular complications associated with diabetes mellitus, and damage to the endothelial glycocalyx has been demonstrated to participate in this process. Ginsenoside $\operatorname{Rg} 1(\operatorname{Rg} 1)$, the major active component isolated from Panax notoginseng, is widely applied for the protection against vascular injury. The present study aimed to analyze the effect of high glucose on endothelial barrier function and its association with endothelial glycocalyx in human umbilical vein endothelial cells (HUVECs), and explore the potential benefits of $\mathrm{Rg} 1$ in protecting endothelial barrier function from high glucose-induced injury. The results indicated that high glucose induced a disorder of the endothelial glycocalyx and increased heparanase mRNA expression in HUVECs, which was reversed by Rg1 treatment. In addition, $\operatorname{Rg} 1$ treatment reduced transendothelial electrical resistance and transendothelial albumin passage after high-glucose stimulation. The present study suggested that high glucose caused a disruption in the endothelial glycocalyx
\end{abstract}

Correspondence to: Professor Youhua Xu, State Key Laboratory of Quality Research in Chinese Medicine, Macau University of Science and Technology, Building H, Avenida Wai Long, Taipa, Macau 999078, P.R. China

E-mail:yhxu@must.edu.mo

Professor Junming Fan, Department of Nephrology, The Research Center of Combined Traditional Chinese and Western Medicine, Affiliated Traditional Chinese Medicine Hospital, Southwest Medical University, Lab Building, Zhongshan Road, Luzhou, Sichuan 646000, P.R. China

E-mail: fanjunminglz@163.com

Key words: endothelial barrier dysfunction, endothelial glycocalyx, heparanase, ginsenoside $\operatorname{Rg} 1$ and increased heparanase expression, which finally resulted in endothelial barrier dysfunction in HUVECs. Of note, Rg1 has a protective effect on high glucose-induced endothelial barrier dysfunction by attenuating the associated increase in heparanase expression.

\section{Introduction}

Diabetes, also known as diabetes mellitus (DM), has an increased morbidity and mortality and represents a serious public health issue worldwide $(1,2)$. Vascular complications are involved in pathological changes of DM $(3,4)$ and are the leading cause of mortality in this population. The endothelium, covering the luminal surface of all blood vessels, has a key role in the maintenance of vascular homeostasis $(5,6)$. Endothelial dysfunction initiates vascular pathogenesis and may finally lead to diabetic vasculopathy (7). The luminal surface of endothelial cells is covered by a thick layer of glycocalyx, which is composed of proteoglycans (PGs) and glycoproteins $(8,9)$. Therefore, dysfunction of glycocalyx may promote the development of diabetic vasculopathy.

It has been demonstrated that endothelial glycocalyx has a significant impact on factors including vascular permeability (10), inflammation (11), coagulation (12) and mechanotransduction (13). It was observed that the thickness of the glycocalyx was altered and its integrity was disrupted in a streptozocin-induced animal model of diabetes (14). Diabetic patients are characterized by endothelial glycocalyx damage, the severity of which is associated with vascular damage $(15,16)$. An in vitro study also observed that hyperglycemia induced glycocalyx dysfunction in either microvascular or macrovascular endothelial cells $(17,18)$. It has been reported that the loss of glycocalyx leads to a reduction in endothelial surface charge and accelerates atherosclerosis in patients with type 2 diabetes (19). Taken together, these studies indicate that glycocalyx dyfunction drives the development of vascular complications in diabetes. 
Panax notoginseng is one of the most commonly used Chinese herbal medicines due to its efficacy in promoting blood circulation and removing blood stasis (20). It is frequently used in the management of diabetes in Asian countries (21) and also possesses cardiovascular protection effects by preserving endothelial cell function and inhibiting thermogenesis (22). Ginsenoside Rg1 (Rg1; Fig. 1), the major active component isolated from Panax notoginseng, appears to be accountable for its extensive pharmacological actions, including anti-oxidant, anti-inflammatory and anti-cancer effects (23). Rg1 has been demonstrated to have cardiovascular protection effects, and may be of potential preventive and therapeutic value for cardiovascular injury in diabetic patients $(24,25)$. In addition, $\operatorname{Rg} 1$ has been demonstrated to be potent in improving renal function and attenuating diabetes-induced renal damage $(26,27)$. However, the underlying mechanisms remain to be elucidated.

Based on the above, the presents study hypothesized that Rg1 may attenuate diabetes-induced vascular dysfunction via restoring the loss of endothelial glycocalyx. To test this hypothesis, the effect of high glucose on the endothelial glycocalyx and endothelial barrier function, and the potential benefits of Rg1 in protecting endothelial barrier function from high glucose-induced endothelial cell injury were investigated.

\section{Materials and methods}

Cell culture. Human umbilical vein endothelial cells (HUVECs) were purchased from the American Type Culture Collection (Manassas, VA, USA). The cells were cultured in low-glucose Dulbecco's modified Eagle's medium (DMEM; Gibco; Thermo Fisher Scientific, Inc., Waltham, MA, USA) containing $5.5 \mathrm{mmol} / 1 \mathrm{D}$-glucose, supplemented with L-glutamine, $10 \%$ fetal bovine serum (FBS; Gibco; Thermo Fisher Scientific, Inc.), $100 \mathrm{U} / \mathrm{ml}$ penicillin and $100 \mu \mathrm{g} / \mathrm{ml}$ streptomycin at $37^{\circ} \mathrm{C}$ in an incubator containing $5 \% \mathrm{CO}_{2}$. Cells were seeded into cell culture dishes and cultured until confluent.

Treatment. For control and high-glucose treatment, HUVECs were cultured with DMEM containing 5.5 and $30 \mathrm{mmol} / \mathrm{l}$ D-glucose, respectively. For drug treatment, the cells were incubated with high-glucose DMEM, and at the same time, Rg1 (>98\% pure; DiDa Kexiang Biological Co., Ltd., Guizhou, China) was added to the culture at concentrations ranging from $10^{-8}$ to $10^{-5} \mathrm{~mol} / \mathrm{l}$ for 1 or 3 days.

Reverse transcription-quantitative polymerase chain reaction $(R T-q P C R)$. Total RNA was extracted from HUVECs using TRIzol reagent (Thermo Fisher Scientific, Inc.). RNA was reverse-transcribed into complementary (c)DNA using the RevertAid First Strand cDNA Synthesis kit (Thermo Fisher Scientific, Inc.). The mRNA levels of heparanase (HPSE) were quantified with an RT-qPCR system (Mastercycler realplex2; Eppendorf, Hamburg, Germany), using SYBR Green SuperMix (Roche Diagnostics, Mannheim, Germany) with appropriate primers pairs. Sequences of primers used in the present study were as follows: HPSE forward, 5'-CCAAAG TTGCTGCTTGCATC-3' and reverse, 5'-AGTGTCCCAGTG TCTCTCAA-3'; GAPDH forward, 5'-CTGGGCTACACT
GAGCACC-3' and reverse, 5'-AAGTGGTCGTTGAGGGCA ATG-3'. The reaction was started by pre-incubation at $95^{\circ} \mathrm{C}$ for $10 \mathrm{~min}$, followed by 40 cycles of amplification $\left(95^{\circ} \mathrm{C}\right.$ for $15 \mathrm{sec}, 65^{\circ} \mathrm{C}$ for $15 \mathrm{sec}$ and $72^{\circ} \mathrm{C}$ for $20 \mathrm{sec}$ ). Gene expression levels of HPSE were normalized to those of the reference gene GAPDH measured in the same sample and the results were analyzed by the $2^{-\Delta \Delta \mathrm{Cq}}$ method (28).

Western blot analysis. Total proteins were prepared using the lysis buffer $(20 \mathrm{mmol} / \mathrm{l}$ Tris, $\mathrm{pH} 7.4,150 \mathrm{mmol} / \mathrm{l} \mathrm{NaCl}$, $1 \mathrm{mmol} / 1$ EDTA, $1 \mathrm{mmol} / \mathrm{EEGTA}, 1 \%$ Triton $\mathrm{X}-100$, $2.5 \mathrm{mmol} / 1 \mathrm{deoxycholic} \mathrm{acid,} 1 \mathrm{mmol} / 1 \beta$-glycerophosphate and $1 \mathrm{mmol} / 1 \mathrm{Na}_{3} \mathrm{VO}_{4}$ ), supplemented with protease inhibitors. Protein concentration was determined using a BCA protein assay kit (Beyotime Institute of Biotechnology, Haimen, China) according to the manufacturer's protocol. The protein of each sample $(25 \mu \mathrm{g})$ was separated using $10 \%$ SDS-PAGE and then transferred to polyvinylidene difluoride membranes (EMD Millipore, Billerica, MA, USA). After blocking with $5 \%$ fat-free milk for $1 \mathrm{~h}$ at room temperature, the membranes were incubated with the following respective primary antibodies: Syndecan-1 monoclonal antibody (1:1,000 dilution; cat. no. ab128936; Abcam, Cambridge, MA, USA), glypican-1 polyclonal antibody (1:1,000 dilution; cat. no. NBP1-33197; Novus Biologicals LLC, Littleton, CO, USA) and GAPDH monoclonal antibody (1:1,000 dilution; cat. no. sc32233; Santa Cruz Biotechnology, Inc., Dallas, TX, USA) at $4^{\circ} \mathrm{C}$ overnight. The membranes were then gently washed for three times ( $5 \mathrm{~min}$ each) and incubated with horseradish peroxide-conjugated goat anti-rabbit secondary antibody (1:3,000 dilution; cat. no. ZB2301; Zhongshan Goldenbridge Bio, Beijing, China) at room temperature for $1.5 \mathrm{~h}$. After washing, the protein bands were visualized with chemiluminescent substrate (EMD Millipore) for $1 \mathrm{~min}$, and capturing of images and densitometric analysis were performed using an imaging station (Bio-Rad Laboratoris, Inc., Hercules, CA, USA). The relative protein expression levels were normalized to GAPDH and the ratio was compared with that of the control group.

Detection of endothelial surface glycocalyx. Wheat germ agglutinin (WGA) from Triticum vulgaris binds to sugar moieties of glycocalyx present on the cell surface, the majority of which are likely to be PG constituents of glycocalyx. Therefore, endothelial surface glycocalyx was labeled by fluorescein isothiocyanate (FITC)-conjugated WGA lectin as previously reported (29). Cells were grown to confluence on glass coverslips and fixed in $4 \%$ paraformaldehyde for $10 \mathrm{~min}$. After being washed for three times, the cells were incubated with FITC-WGA lectin (Sigma-Aldrich; Merck KGaA, Darmstadt, Germany) at $2 \mu \mathrm{g} / \mathrm{ml}$ for $30 \mathrm{~min}$. Coverslips were mounted and visualized using a fluorescence microscope (Leica Microsystems, Wetzlar, Germany).

Transendothelial electrical resistance (TEER) measurement. Cells were seeded onto microporous polyester membranes (0.4- $\mu \mathrm{m}$ pore size) of Transwell filter inserts (Corning Inc., Corning, NY, USA). The cells were grown onto the upper chamber of the Transwell until confluent. The HUVECs were stimulated with vehicle, $30 \mathrm{mmol} / 1$ high glucose or $\mathrm{Rg} 1$ for $24 \mathrm{~h}$ as indicated. The TEER of the monolayer of HUVECS 


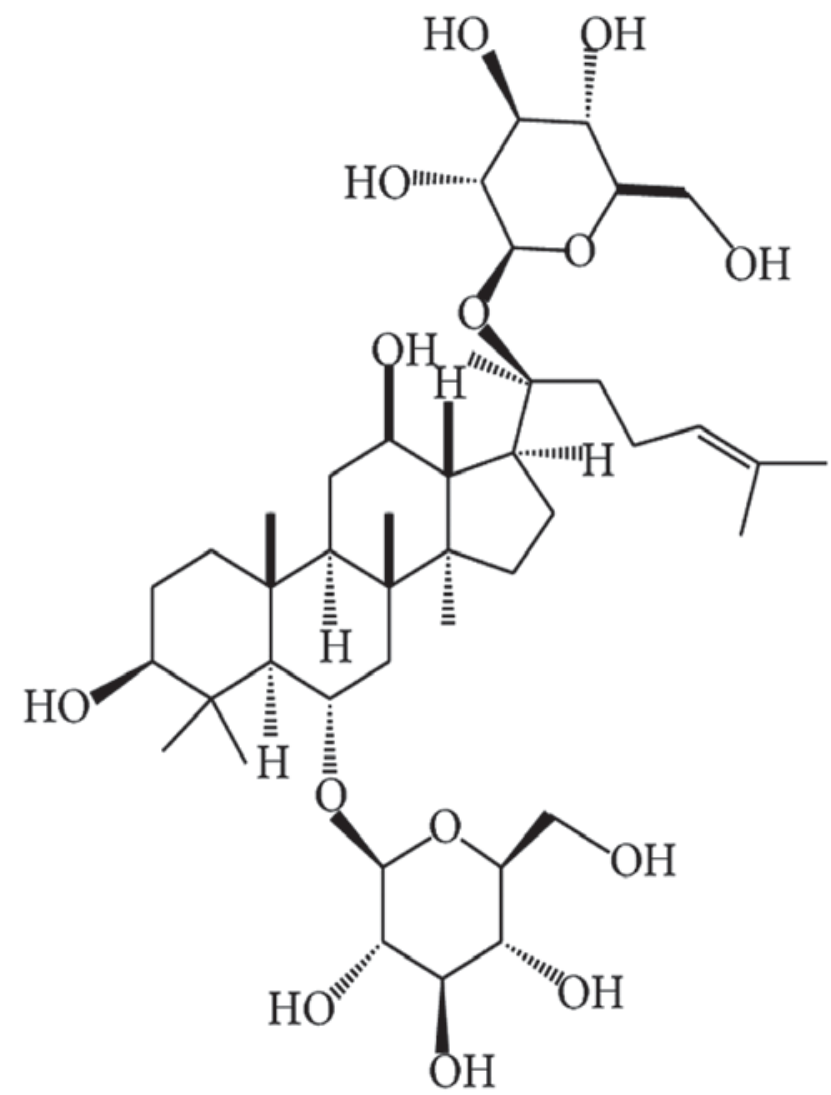

Figure 1. Chemical structure of ginsenoside Rg1.

was measured using a Millicell ERS-2 Volt-Ohm meter (EMD Millipore) according to the protocol of a previous study (30). After subtraction of the value determined using a blank, cell-free filter, the mean value of the TEER was expressed in common units $\left(\Omega \mathrm{cm}^{2}\right)$. TEER values of a vehicle-treated monolayer of endothelial cells were designated as baseline values. The percentage of TEER relative to baseline value was calculated via the following formula: TEER $\%=($ TEER of experimental wells/baseline TEER of experimental wells) $\mathrm{x} 100 \%$.

Transendothelial albumin passage. The transendothelial passage of albumin was analyzed by measuring the passage of FITC-labeled bovine serum albumin (BSA; Sigma-Aldrich; Merck $\mathrm{KGaA}$ ) across the monolayer as described previously (31). In brief, cells were seeded onto the upper chambers of Transwells and allowed to grow to confluence as described above. The medium in the insert was replaced with serum-free medium (SFM) containing $0.5 \mathrm{mg} / \mathrm{ml}$ FITC-labelled BSA and the medium in the well was replaced by SFM only. After 1, 2 and $3 \mathrm{~h}$ of incubation, the medium was collected from each well, and the fluorescence of the aliquots was measured on a fluorometer with excitation at $495 \mathrm{~nm}$ and emission at $520 \mathrm{~nm}$. The amount of albumin passing the endothelial cell monolayer was calculated with a standard curve generated from a set of FITC-labeled BSA dilutions.

Statistical analyses. All data were analyzed using SPSS software (version 17.0; SPSS, Inc., Chicago, IL, USA). Values are expressed as the mean \pm standard deviation. The independent
Student's t-test and one-way analysis of variance (ANOVA) with a least significant difference (LSD) post hoc test, were used for comparison between groups. $\mathrm{P}<0.05$ was considered to indicate a statistically significant difference.

\section{Results}

Effect of Rgl on the PG core proteins in high glucose-induced HUVECs. PG core proteins are important constituents of glycocalyx on the cell surface. Expression of PG core proteins syndecan-1 and glypican-1 was analyzed by western blot analysis after exposure to high glucose for different durations (Fig. 2). It was demonstrated that syndecan-1 was gradually decreased in HUVECs incubated with high glucose from 1-4 days. Over the same duration, the expression of glypican-1 was also decreased by high-glucose stimulation, with the changes being significant at 3 and 4 days (Fig. 2A). HUVECs under high-glucose stimulation were then treated with different concentrations of $\mathrm{Rg} 1$ for 3 days. It was observed that treatment with Rg1 increased PG core proteins in HUVECs at concentrations ranging from $10^{-8}$ to $10^{-5} \mathrm{~mol} / \mathrm{l}$ and a significant difference was identified at $10^{-5} \mathrm{~mol} / \mathrm{l}$ (Fig. 2B).

High glucose-induced HPSE expression is attenuated by $\mathrm{Rg} 1$ treatment in HUVECs. To assess the effects of high glucose and Rg1 treatment on HPSE expression, HUVECs were incubated with $30 \mathrm{mmol} / 1$ glucose and different concentrations of Rg1 as indicated. The expression of HPSE mRNA was detected by RT-qPCR. It was observed that HPSE mRNA expression in high glucose-treated cells was rapidly increased and reached a peak at 1 day, and then it returned to baseline levels at 3 and 4 days (Fig. 3A). To observe the effect of Rg1, HUVECs were first incubated with high glucose, followed by different concentrations of $\mathrm{Rg} 1$ for 1 day. It was indicated that HPSE expression in HUVECs was reduced by treatment with $\mathrm{Rg} 1$ at concentrations ranging from $10^{-8}$ to $10^{-5} \mathrm{~mol} / \mathrm{l}$, and a significant difference was observed at $10^{-7} \mathrm{~mol}$ (Fig. 3B).

Rgl prevents the disruption of the glycocalyx induced by high glucose. WGA-FITC, which binds to sugar residues on cell surface, was used to quantify the expression of glycocalyx in HUVECs. A marked reduction in WGA-FITC binding was observed in high glucose-induced cells compared with untreated controls, suggesting the disruption of endothelial glycocalyx. As expected, the expression of glycocalyx was increased by treatment with $\mathrm{Rg} 1$, indicating that $\mathrm{Rg} 1$ prevented the loss of glycocalyx and attenuated the disruption of the glycocalyx in HUVECs incubated with $30 \mathrm{mmol} / \mathrm{l}$ glucose (Fig. 4).

Rgl treatment increases TEER in the presence of high glucose. TEER is associated with the integrity of cell monolayers. Its decline represents an increase in the passage of water and small molecules across the cell monolayer and an impaired cell barrier function. To study the effects of Rg1 treatment on TEER, HUVECs were stimulated with high glucose in the presence or absence of Rg1. High glucose caused a modest reduction in the mean TEER by up to $20 \%$ relative to that in the controls, which was inhibited in the presence of Rg1 (Fig. 5A). 
A
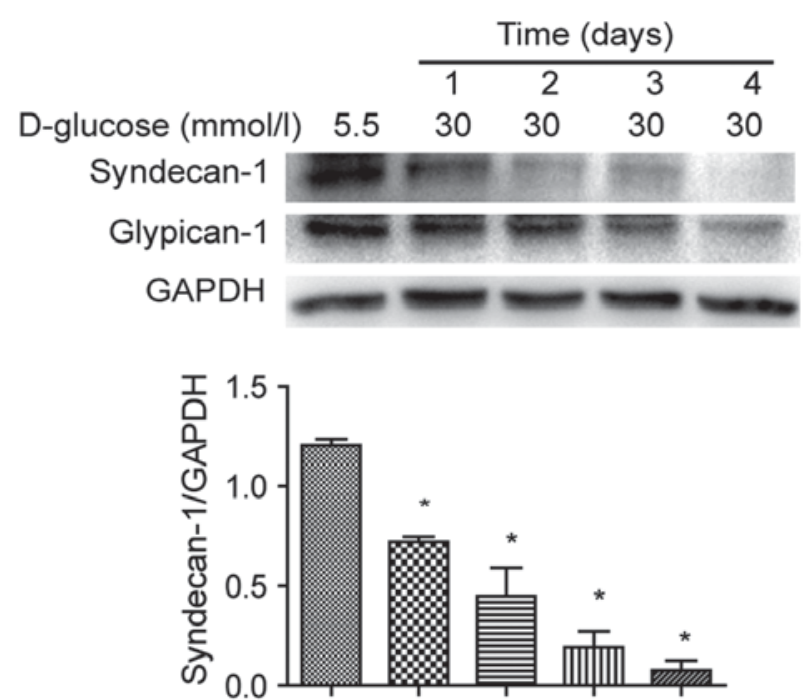

D-glucose (mmol/l) $5.5 \quad 30 \quad 30 \quad 30 \quad 30$

\begin{tabular}{cccc}
1 & 2 & 3 & 4 \\
\hline \multicolumn{3}{c}{ Time (days) }
\end{tabular}

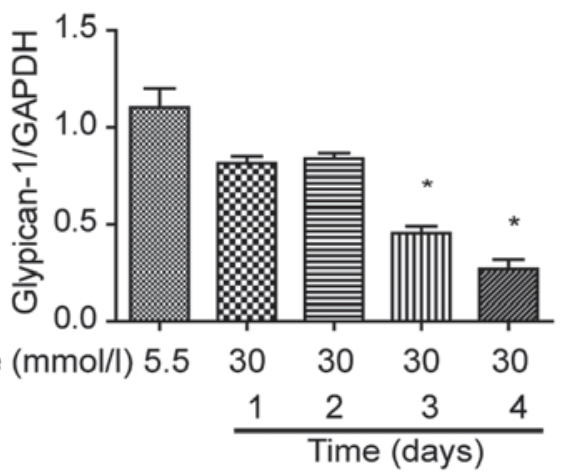

B

D-glucose $(\mathrm{mmol} / \mathrm{l}) \quad \begin{array}{llllll}5.5 & 30 & 30 & 30 & 30 & 30\end{array}$

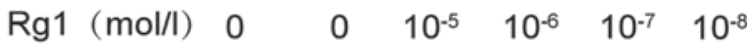

Syndecan-1

Glypican-1 GAPDH

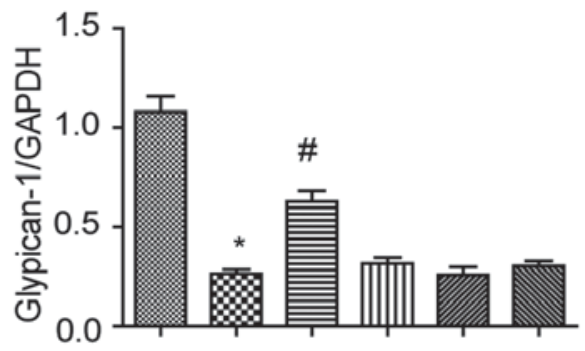

D-glucose $(\mathrm{mmol} / \mathrm{l}) \begin{array}{llllll}5.5 & 30 & 30 & 30 & 30 & 30\end{array}$

$\begin{array}{llllllll}\mathrm{Rg} 1 & (\mathrm{~mol} / \mathrm{l}) & 0 & 0 & 10^{-5} & 10^{-6} & 10^{-7} & 10^{-8}\end{array}$

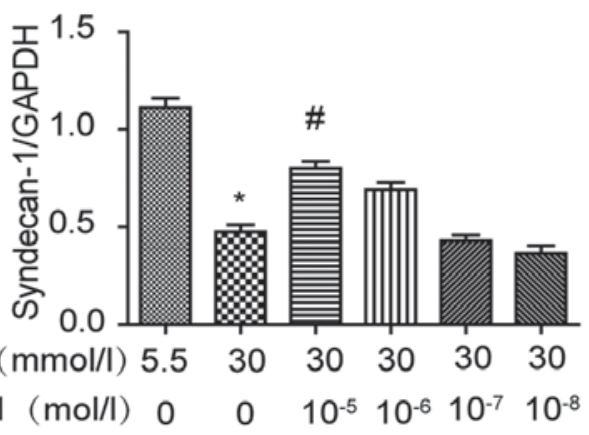

Figure 2. Expression of proteoglycan core proteins in high glucose-induced HUVECs. (A) HUVECs were incubated with $30 \mathrm{mmol} / 1$ glucose for $1,2,3$ and 4 days. (B) HUVECs were treated with $30 \mathrm{mmol} / 1$ glucose and various concentrations of Rg1 for 3 days. Specific antibody was used to detect syndecan-1, glypican-1 by western blotting. Quantified values are expressed as the mean \pm standard deviation $(n=3) . ~ " P<0.05$ vs. normal glucose; ${ }^{*} \mathrm{P}<0.05$ vs. high glucose group. HUVECS, human umbilical vein endothelial cells; Rg1, ginsenoside Rg1.

A

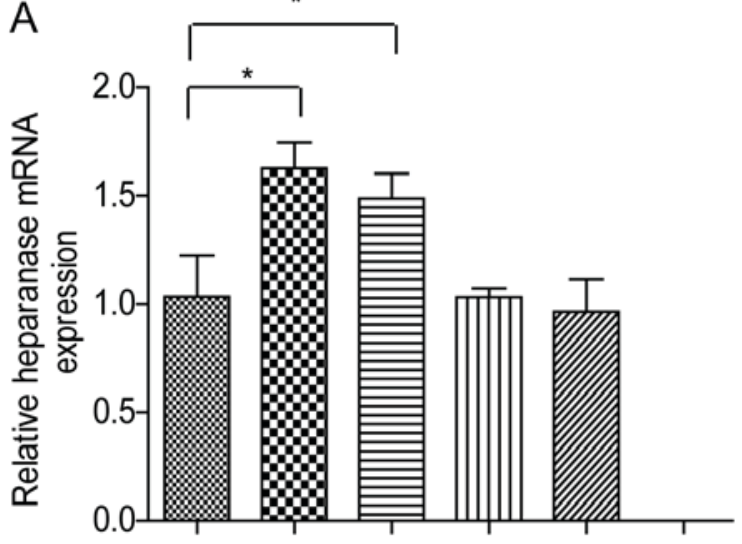

D-glucose (mmol/l) $\begin{array}{lllll}5.5 & 30 & 30 & 30 & 30\end{array}$

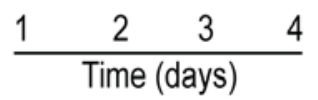

B

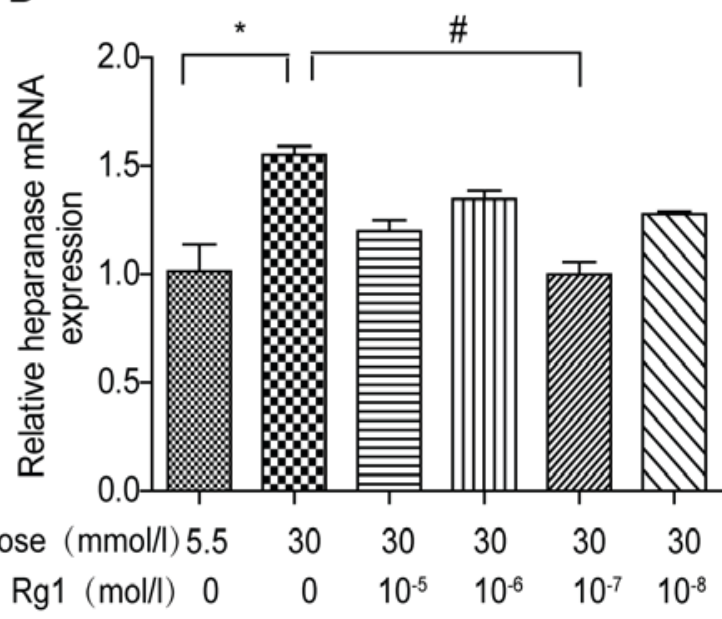

Figure 3. High glucose-induced heparanase expression in human umbilical vein endothelial cells. (A) Heparanase mRNA expression was increased by treatment with $30 \mathrm{mmol} / 1$ glucose for 1 and 2 days, and (B) reduced by treatment with Rg1. Values are expressed as the mean \pm standard deviation ( $\mathrm{n}=3$ ). ${ }^{*} \mathrm{P}<0.05$ vs. normal glucose; ${ }^{~} \mathrm{P}<0.05$ vs. high glucose group. $\mathrm{Rg} 1$, ginsenoside $\mathrm{Rg} 1$. 

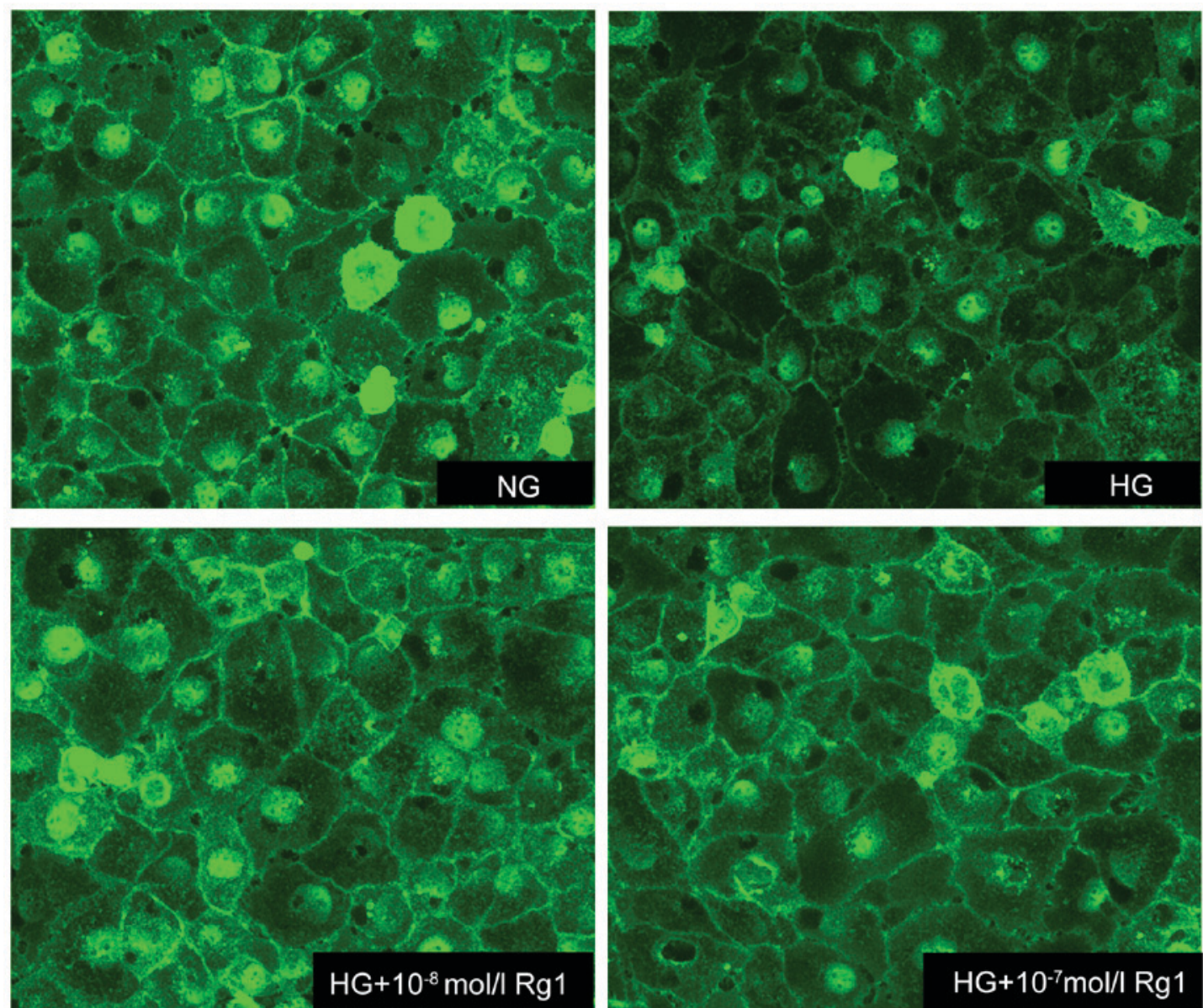

Figure 4. Expression of WGA in HG-induced HUVECs. Fluorescence microscopy after labeling the glycocalyx of HUVECs with WGA-FITC lectin (magnification, $\mathrm{x} 200$ ). The binding of WGA-FITC lectin was reduced by treatment with HG, while this effect was attenuated by Rg1. WGA, wheat germ agglutinin; FITC, fluorescein isothiocyanate; HUVECS, human umbilical vein endothelial cells; Rg1, ginsenoside Rg1; HG, high glucose; NG, normal glucose.
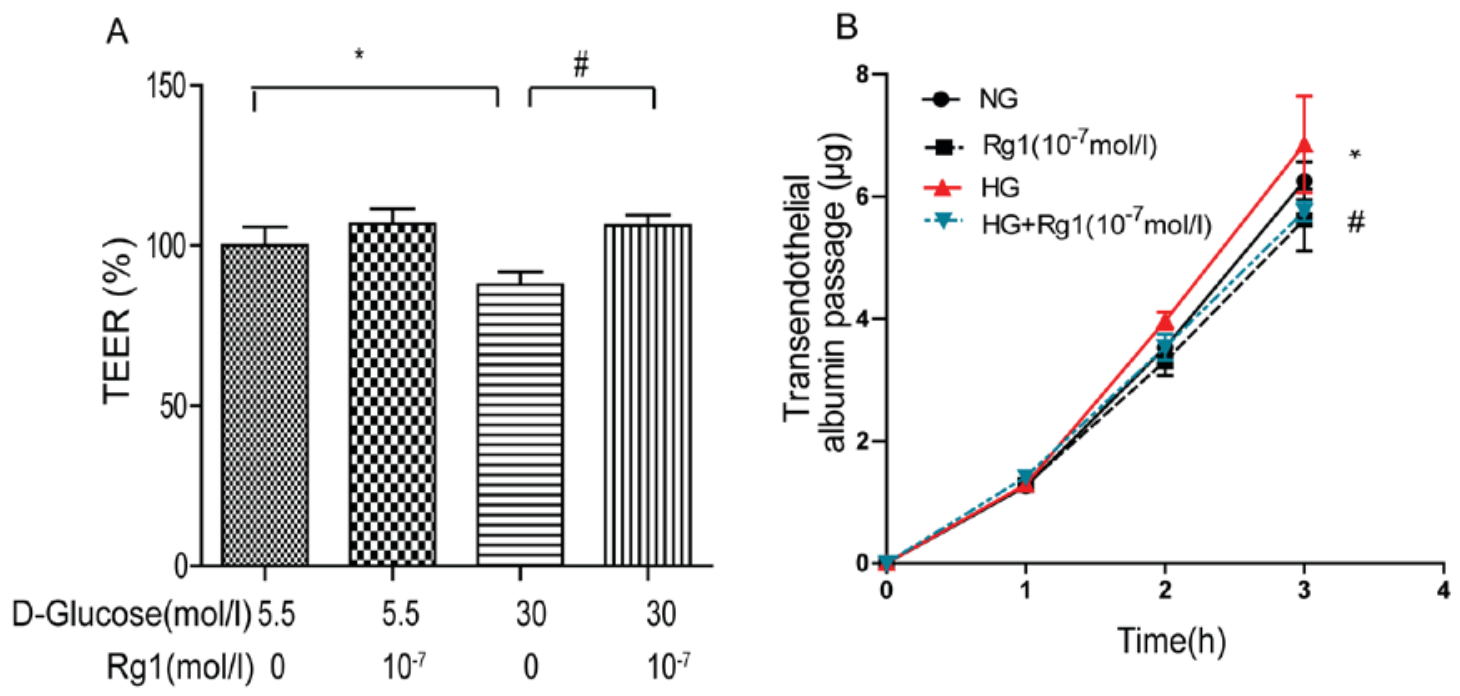

Figure 5. Influence of HG and Rg1 on endothelial barrier function in HUVECs. (A) HG decreased the TEER of HUVECs, which was inhibited by Rg1. (B) HG increased transendothelial albumin passage of HUVECs. Cumulative passage of fluorescein isothiocyanate-labeled albumin across the HUVECs monolayer was determined over time. Values are expressed as the mean \pm standard deviation $(\mathrm{n}=3)$. ${ }^{\mathrm{P}}<0.05 \mathrm{HG}$ vs. NG; ${ }^{\mathrm{P}} \mathrm{P}<0.05 \mathrm{HG}+\mathrm{Rg} 1\left(10^{-7} \mathrm{~mol} / \mathrm{l}\right)$ vs. $\mathrm{HG}$ group. $\mathrm{Rg} 1$, ginsenoside Rg1; HUVECS, human umbilical vein endothelial cells; TEER, transendothelial electrical resistance; HG, high glucose; NG, normal glucose.

High glucose leads to increased transendothelial albumin passage that is attenuated by treatment with Rgl. Since $30 \mathrm{mmol} / \mathrm{l}$ high glucose leads to decreased TEER, it was examined whether $\operatorname{Rg} 1$ was able to preserve the permeability of cultured HUVEC monolayers. The permeability was assessed by measuring the passage of FITC-labeled BSA across the 
monolayer, i.e., the transendothelial albumin passage. As presented in Fig. 5B, stimulation with $30 \mathrm{mmol} / \mathrm{l}$ high glucose significantly increased transendothelial albumin passage across HUVECs, while this effect was inhibited in the presence of Rg1.

\section{Discussion}

A pivotal role of the endothelium is to serve as a regulated barrier to partially separate the contents of the blood from the extravascular space (32). The endothelial glycocalyx covers the luminal surface of the vascular endothelium $(33,34)$, and is responsible for endothelial barrier function. Widespread loss of the endothelial surface glycocalyx leads to damage of vascular function and an elevation in the microvascular permeability to water as well as albumin, and results in systemic vascular dysfunction in proteinuric kidney disease (35). The results of the present study indicated a marked decrease in the PG core proteins syndecan-1 and glypican-1 on HUVECs after exposure to high glucose, while treatment with Rg1 increased the formation of PG core proteins. This was further confirmed in an assay using WGA-FITC lectin, in which WGA-FITC lectin binding was markedly reduced after high-glucose treatment, while this reduction was inhibited by $\mathrm{Rg} 1$ treatment. These results suggested that treatment with $\mathrm{Rg} 1$ increased the formation of PG and enhanced the integrity of the endothelial cell monolayer, which is beneficial for preserving endothelial barrier function under a high-glucose conditions.

In response to persistent activators of the endothelium, i.e., in diabetes mellitus, hypertension and systemic inflammation, endothelial cells undergo pathological changes $(36,37)$, including the induction of the expression of certain enzymes, including HPSE. HPSE, a degrading enzyme of the endothelial cell glycocalyx, is the only known mammalian enzyme to cleave PGs (38). It has been reported that increased HPSE expression causes damage to the glycocalyx of mouse glomerular endothelial cells and increases the trans-endothelial albumin passage of the cell monolayer (39). The present study indicated that high glucose increased HPSE mRNA expression on HUVECs at the early stage of high-glucose treatment, whereas Rg1 reduced the increase of HPSE induced by high glucose. The results indicated that $\mathrm{Rg} 1$ inhibited the production of HPSE to ameliorate endothelial glycocalyx disorders.

Endothelial glycocalyx is located between the blood stream and the endothelium, provides a barrier for certain molecules, and has an important role in endothelial permeability and endothelial functions $(40,41)$. A significant degradation of the glomerular glycocalyx has been reported in the setting of diabetes in that loss of glycocalyx increases vascular permeability (16). In, TEER is used as an indicator of the passage of water and small molecules across a cell layer. TEER is regarded as a measure of the resistance to the passage of ions across a confluent cell monolayer. In the present study, the passage of albumin across cell monolayers was tested to evaluate the permeability of the endothelial cell monolayer, and the results indicated that $\mathrm{Rg} 1$ attenuated the damage of endothelial barrier function by enhancing TEER and decreasing the cell transendothelial albumin passage.

In conclusion, the present study demonstrated that $\mathrm{Rg} 1$ inhibited the loss of endothelial glycocalyx and HPSE mRNA expression, and increased TEER, while decreasing endothelial cell monolayer permeability and protecting endothelial barrier function. The present results may provide a novel mechanism of action of $\mathrm{Rg} 1$ in the treatment of diabetic vasculopathy.

\section{Acknowledgements}

This study was supported by the Science and Technology Development Fund of Macau (grant no. 071/2014/A), the Education Department Program of Sichuan Province (grant no. 17TD0046), the Key Project of the Health Department of Sichuan Province (grant no. 16ZD034) and the Innovative Research Team of Luzhou (grant no. 2016LZXNYD-T05).

\section{Competing interests}

The authors declare that they have no competing interests.

\section{References}

1. García-Pérez LE, Alvarez M, Dilla T, Gil-Guillén V and Orozco-Beltrán D: Adherence to therapies in patients with type 2 diabetes. Diabetes Ther 4: 175-194, 2013.

2. Shaw JE, Sicree RA and Zimmet PZ: Global estimates of the prevalence of diabetes for 2010 and 2030. Diabetes Res Clin Pract 87: 4-14, 2010.

3. Potenza MA, Gagliardi S, Nacci C, Carratu' MR and Montagnani M: Endothelial dysfunction in diabetes: From mechanisms to therapeutic targets. Curr Med Chem 16: 94-112, 2009.

4. Santi D, Giannetta E, Isidori AM, Vitale C, Aversa A and Simoni M: Therapy of endocrine disease: Effects of chronic use of phosphodiesterase inhibitors on endothelial markers in type 2 diabetes mellitus: A meta-analysis. Eur J Endocrinol 172: R103-R114, 2015.

5. Bertoluci MC, Cé GV, da Silva AM, Wainstein MV, Boff W and Punales M: Endothelial dysfunction as a predictor of cardiovascular disease in type 1 diabetes. World J Diabetes 6: 679-692, 2015.

6. Widlansky ME, Gokce N, Keaney JF Jr and Vita JA: The clinical implications of endothelial dysfunction. J Am Coll Cardiol 42: 1149-1160, 2003.

7. De Vriese AS, Verbeuren TJ, Van de Voorde J, Lameire NH and Vanhoutte PM: Endothelial dysfunction in diabetes. Br J Pharmacol 130: 963-974, 2000.

8. Pries AR, Secomb TW and Gaehtgens P: The endothelial surface layer. Pflugers Arch 440: 653-666, 2000.

9. Reitsma S, Slaaf DW, Vink H, van Zandvoort MA and oude Egbrink MG: The endothelial glycocalyx: Composition, functions, and visualization. Pflugers Arch 454: 345-359, 2007.

10. Salmon AH and Satchell SC: Endothelial glycocalyx dysfunction in disease: Albuminuria and increased microvascular permeability. J Pathol 226: 562-574, 2012.

11. Mulivor AW and Lipowsky HH: Inflammation-and ischemia-induced shedding of venular glycocalyx. Am J Physiol Heart Circ Physiol 286: H1672-H1680, 2004.

12. Pearson MJ and Lipowsky HH: Effect of fibrinogen on leukocyte margination and adhesion in postcapillary venules. Microcirculation 11: 295-306, 2004.

13. Tarbell JM and Pahakis MY: Mechanotransduction and the glycocalyx. J Intern Med 259: 339-350, 2006.

14. Dogné S, Rath G, Jouret F, Caron N, Dessy C and Flamion B: Hyaluronidase 1 deficiency preserves endothelial function and glycocalyx integrity in early streptozotocin-induced diabetes. Diabetes 65: 2742-2753, 2016.

15. Nieuwdorp M, Mooij HL and Kroon J, Atasever B, Spaan JA, Ince C, Holleman F, Diamant M, Heine RJ, Hoekstra JB, et al: Endothelial glycocalyx damage coincides with microalbuminuria in type 1 diabetes. Diabetes 55: 1127-1132, 2006.

16. Broekhuizen LN, Lemkes BA and Mooij HL, Meuwese MC, Verberne H, Holleman F, Schlingemann RO, Nieuwdorp M, Stroes ES and Vink H: Effect of sulodexide on endothelial glycocalyx and vascular permeability in patients with type 2 diabetes mellitus. Diabetologia 53: 2646-2655, 2010. 
17. Pahwa R, Nallasamy $P$ and Jialal I: Toll-like receptors 2 and 4 mediate hyperglycemia induced macrovascular aortic endothelial cell inflammation and perturbation of the endothelial glycocalyx. J Diabetes Complications 30: 563-572, 2016.

18. Singh A, Fridén V, Dasgupta I, Foster RR, Welsh GI, Tooke JE, Haraldsson B, Mathieson PW and Satchell SC: High glucose causes dysfunction of the human glomerular endothelial glycocalyx. Am J Physiol Renal Physiol 300: F40-F48, 2011.

19. Nassimizadeh M, Ashrafian H, Drury NE, Howell NJ, Digby J, Pagano D, Frenneaux MP and Born GV: Reduced negative surface charge on arterial endothelium explains accelerated atherosclerosis in type 2 diabetic patients. Diab Vasc Dis Res 7: 213-215, 2010.

20. Yang X, Xiong X, Wang $\mathrm{H}$ and Wang J: Protective effects of panax notoginseng saponins on cardiovascular diseases: A comprehensive overview of experimental studies. Evid Based Complement Alternat Med 2014: 204840, 2014.

21. Uzayisenga R, Ayeka PA and Wang Y: Anti-diabetic potential of Panax notoginseng saponins (PNS): A review. Phytother Res 28: 510-516, 2014

22. Ling S, Nheu L, Dai A, Guo Z and Komesaroff P: Effects of four medicinal herbs on human vascular endothelial cells in culture. Int J Cardiol 128: 350-358, 2008.

23. Lü JM, Yao Q and Chen C: Ginseng compounds: An update on their molecular mechanisms and medical applications. Curr Vasc Pharmacol 7: 293-302, 2009.

24. Yu HT, Zhen J, Pang B, Gu JN and Wu SS: Ginsenoside Rg1 ameliorates oxidative stress and myocardial apoptosis in streptozotocin-induced diabetic rats. J Zhejiang Univ Sci B 16: 344-354, 2015.

25. Yu H, Zhen J, Yang Y, Gu J, Wu S and Liu Q: Ginsenoside Rg1 ameliorates diabetic cardiomyopathy by inhibiting endoplasmic reticulum stress-induced apoptosis in a streptozotocin-induced diabetes rat model. J Cell Mol Med 20: 623-631, 2016.

26. Zhang LN, Xie XS, Zuo C and Fan JM: Effect of ginsenoside Rgl on the expression of TNF-alpha and MCP-1 in rats with diabetic nephropathy. Sichuan Da Xue Xue Bao Yi Xue Ban 40: 466-471, 2009 (In Chinese)

27. Ma X, Xie X, Zuo C and Fan J: Effects of ginsenoside Rg1 on streptozocin-induced diabetic nephropathy in rats. Sheng Wu Y Xue Gong Cheng Xue Za Zhi 27: 342-347, 2010 (In Chinese).

28. Livak KJ and Schmittgen TD: Analysis of relative gene expression data using real-time quantitative PCR and the 2(-Delta Delta C(T)) method. Methods 25: 402-408, 2001

29. Singh A, Satchell SC, Neal CR, McKenzie EA, Tooke JE and Mathieson PW: Glomerular endothelial glycocalyx constitutes a barrier to protein permeability. J Am Soc Nephrol 18: 2885-2893, 2007.
30. Zhang W, Xu Q, Wu J, Zhou X, Weng J, Xu J, Wang W, Huang Q and Guo X: Role of src in vascular hyperpermeability induced by advanced glycation end products. Sci Rep 5: 14090, 2015.

31. Garsen M, Sonneveld R, Rops AL, Huntink S, van Kuppevelt TH, Rabelink TJ, Hoenderop JG, Berden JH, Nijenhuis T and van der Vlag J: Vitamin D attenuates proteinuria by inhibition of heparanase expression in the podocyte. J Pathol 237: 472-481, 2015.

32. Xu C, Wu X, Hack BK, Bao L and Cunningham PN: TNF causes changes in glomerular endothelial permeability and morphology through a Rho and myosin light chain kinase-dependent mechanism. Physiol Rep 3: e12636, 2015.

33. Haraldsson B and Nyström J: The glomerular endothelium: New insights on function and structure. Curr Opin Nephrol Hypertens 21: 258-263, 2012.

34. Fridén V, Oveland E, Tenstad O, Ebefors K, Nyström J, Nilsson UA and Haraldsson B: The glomerular endothelial cell coat is essential for glomerular filtration. Kidney Int 79: 1322-1330, 2011.

35. Salmon AH, Ferguson JK, Burford JL, Gevorgyan H, Nakano D, Harper SJ, Bates DO and Peti-Peterdi J: Loss of the endothelial glycocalyx links albuminuria and vascular dysfunction. J Am Soc Nephrol 23: 1339-1350, 2012.

36. Rabelink TJ, de Boer HC and van Zonneveld AJ: Endothelial activation and circulating markers of endothelial activation in kidney disease. Nat Rev Nephrol 6: 404-414, 2010.

37. Gil N, Goldberg R and Neuman T, Garsen M, Zcharia E, Rubinstein AM, van Kuppevelt T, Meirovitz A, Pisano C, Li JP, et al: Heparanase is essential for the development of diabetic nephropathy in mice. Diabetes 61: 208-216, 2012.

38. van den Hoven MJ, Rops AL, Bakker MA, Aten J, Rutjes N, Roestenberg P, Goldschmeding R, Zcharia E, Vlodavsky I, van der Vlag $\mathbf{J}$ and Berden $\mathbf{J} H$ : Increased expression of heparanase in overt diabetic nephropathy. Kidney Int 70: 2100-2108, 2006

39. Garsen M, Lenoir O, Rops AL, Dijkman HB, Willemsen B, van Kuppevelt TH, Rabelink TJ, Berden JH, Tharaux PL and van der Vlag J: Endothelin-1 induces proteinuria by heparanase-mediated disruption of the glomerular glycocalyx. J Am Soc Nephrol 27: 3545-3551, 2016.

40. Goligorsky MS: Vascular endothelium in diabetes. Am J Physiol Renal Physiol 312: F266-F275, 2017.

41. Sieve I, Münster-Kühnel AK and Hilfiker-Kleiner D: Regulation and function of endothelial glycocalyx layer in vascular diseases. Vascul Pharmacol 100: 26-33, 2018. 